\title{
Visual biofeedback for paradoxical vocal fold motion (PVFM)
}

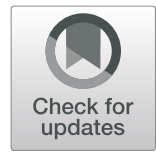

\author{
Rachelle Alyce LeBlanc ${ }^{1}$, Daniel Aalto ${ }^{2}$ and Caroline C. Jeffery ${ }^{1 *}$ (D)
}

\begin{abstract}
Objectives: Paradoxical vocal fold motion (PVFM) is a common condition where the vocal folds inappropriately adduct during inspiration. This results in dyspnea and occasionally significant distress. The condition is thought to be primarily functional, with behavioural therapy considered mainstay in the non-acute setting. However, practice variations and limited access to speech language pathology (SLP) services can pose management challenges. We aimed to examine the efficacy of surgeon performed visual biofeedback as first-line treatment for PVFM.
\end{abstract}

Study design: Prospective, non-randomized, non-comparative clinical study.

Methods: Adult patients referred for possible PVFM and congruent laryngoscopy findings over a two-year period were included. Patients were excluded if they presented in acute distress, had alternate diagnosis to explain symptomology and/or coexisting untreated lower respiratory pathology. Patients underwent immediate surgeonperformed visual biofeedback on the same visit day. The primary outcome of interest was change in Dyspnea Index (DI) scores pre- and post-intervention 3 months follow-up. The secondary outcome measured was change in asthma medication use from baseline to follow-up.

Results: Of 34 patients presenting, 25 met inclusion criteria. Of these, $72 \%$ were female with an average age of $36.9 \pm 14.1$. Approximately $48 \%$ of patients had a diagnosis of well-controlled asthma at presentation and co-morbid psychiatric diagnoses were common (52\%). Pre- and post-intervention analysis showed significant improvement in DI scores $(p<0.001)$ and reduction in bronchodilator use $(p=0.003)$.

Conclusion: This is a prospective study that evaluates the role of visual biofeedback in PVFM patients. Our data suggests that visual biofeedback effectively reduces short-term subjective symptoms and asthma medication use.

Level of evidence: 3

Keywords: Paradoxical vocal fold motion, Biofeedback

\section{Introduction}

Paradoxical vocal fold motion (PVFM) or inducible laryngeal obstruction (ILO) is a common condition characterized by abnormal adduction of the vocal folds during inspiration $[1,2]$. It is within the spectrum of

\footnotetext{
* Correspondence: caroline.jeffery@ahs.ca

This work was presented at the Fall Voice Conference in Dallas, TX on October $19^{\text {th }}, 2019$.

'Division of Otolaryngology Head and Neck Surgery, Department of Surgery, University of Alberta, 1E4 Walter Mackenzie Centre, 8440-112 Street NW, Edmonton, Alberta T6G 2B7, Canada

Full list of author information is available at the end of the article
}

conditions that includes laryngeal hypersensitivity and laryngospasm, where complete adduction and obstruction occurs $[3,4]$. The term vocal cord dysfunction is also commonly used by non-otolaryngologists, but is a problematic term as the vocal folds have normal structure and innervation. The consequent airway obstruction symptoms include stridor, dysphonia, and cough [5]. PVFM is particularly common in women and is often mistaken for asthma, allergic reactions, vocal fold motion abnormalities, and croup [6]. Patients are often misdiagnosed and this often leads to unnecessary intubations, long-term

C C The Author(s). 2021 Open Access This article is licensed under a Creative Commons Attribution 4.0 International License, which permits use, sharing, adaptation, distribution and reproduction in any medium or format, as long as you give appropriate credit to the original author(s) and the source, provide a link to the Creative Commons licence, and indicate if changes were made. The images or other third party material in this article are included in the article's Creative Commons licence, unless indicated otherwise in a credit line to the material. If material is not included in the article's Creative Commons licence and your intended use is not permitted by statutory regulation or exceeds the permitted use, you will need to obtain permission directly from the copyright holder. To view a copy of this licence, visit http://creativecommons.org/licenses/by/4.0/ The Creative Commons Public Domain Dedication waiver (http://creativecommons.org/publicdomain/zero/1.0/) applies to the data made available in this article, unless otherwise stated in a credit line to the data. 
medical and/or surgical therapy [6]. Proper diagnosis is key for avoiding unnecessary treatments.

PVFM is increasingly recognized as a functional disorder rather than psychogenic in etiology [7]. Impaired laryngeal sensitivity, inflammation, gastroesophageal reflux disease, exercise intolerance, and viral illness have all been proposed as potentiating factors described in the literature [7]. Patients usually present with a history of episodic upper airway symptoms, often with audible inspiratory or biphasic stridor, respiratory distress, inability to speak easily and severe anxiety [7, 8]. While laryngoscopy during a symptomatic episode is the considered the gold standard for diagnosis $[1,2]$, physical exam findings between episodes are generally normal. In the non-acute setting, laryngoscopy remains important to excluding any upper airway pathology and can be confirmatory when adduction with inspiration is visualized, with or without provocation maneuvers [9]. Unfortunately, this is not always present and is not considered necessary for making the diagnosis [6].

Treatment options for PVFM include management of comorbid conditions, education, counselling, reassurance, and respiratory retraining. This includes introducing breathing techniques such asa jaw thrust, pursed lip breathing, nose to mouth breathing, panting and sniffing [10-14]. It is hypothesized that these specific techniques interrupt irregular respiratory spasms or patterns [7]. This allows familiar neurologic signals to reengage and relax the vocal folds [7]. Visual biofeedback involves allowing patients to visualize their own breathing patterns during routine flexible nasolaryngoscopy so that patients can modify their own breathing. This form of behavioural therapy gives patients techniques and strategies that can be practiced at home and used during acute attacks to improve their breathing [7, 10].

While multidisciplinary assessment and treatment of PVFM is ideal, this is not always possible. Access to timely specialized speech language pathology (SLP) services can be difficult in many places in Canada, resulting in long wait-times and delays in management. At our institution, wait-times for respiratory retraining therapy with speech language pathology is typically 6 to 9 months. This provided an opportunity to assess the effectiveness of surgeon performed visual biofeedback in the initial management of PVFM. While visual biofeedback has anecdotal effectiveness as an adjunct treatment of PVFM in the otolaryngology and speech language pathology community [15], few prospective studies exist.

\section{Methods}

Institutional review board approval was obtained from the Human Research Ethics Board at the University of Alberta (Pro00076731).

\section{Patient population}

All new patients referred for possible PVFM to a tertiary care laryngology practice between January 1st, 2018 to February 1st, 2020 were approached for participation in the study. Routine history, physical examination, and flexible in-office laryngoscopy was performed in all patients. Patients were excluded from the study if they had known refractory PVFM or were undergoing active SLP therapy. Additional exclusion criteria included patients in acute airway distress or those with untreated laryngeal, airway or lung pathologies. Patients with otherwise normal laryngoscopy underwent provocation maneuvers to elicit inspiratory adduction, but the absence of positive findings did not exclude the diagnosis of PVFM, which is in keeping with the current literature [16].

\section{Intervention}

After topicalization of the nasal cavity with $1 \%$ lidocaine and 0.05\% otrivin 50:50 mixture, surgeon-performed visual biofeedback was administered with continuous laryngoscopy performed using a distal-chip flexible rhinolaryngoscope. The following intervention was provided: explanation of normal laryngeal anatomy and breathing physiology, performance of laryngeal release exercises (e.g. rapid nasal breathing, pursed-lip breathing, etc.) [10, 13, 14]. Patients visualized their larynx throughout and were encouraged to palpate their anterior neck to recognize laryngeal tension, posture, and breathe control during laryngeal release exercises. Follow-up at 3 months and one-year was offered to all patients. Telephone follow-up was performed with patients who could not attend in-clinic follow-up due to geographic distance or patient-specific factors.

\section{Data collection}

Baseline basic demographic information was collected including age, sex, and comorbidities. Specific information such as concurrent diagnosis of asthma, psychiatric illnesses, and smoking status were collected. Specific triggers for PVFM or laryngospasm episodes were also recorded, including exercise, acid reflux, upper respiratory tract infections, and environmental exposures.

\section{Primary outcome measure}

The primary outcome measure was Dyspnea Index score pre- and 3 months post-intervention. The Dyspnea Index Score is a validated tool to measure subjective dyspnea symptom burden and has been previously validated by PVFM patients [17]. It is simple to administer, provides a measure of overall symptom severity, and can be used to monitor treatment progress [17]. The questionnaire was administered to patients in person at each the initial visit and at each follow-up. 


\section{Secondary outcome measures}

Our secondary outcome was change in patient reported use of inhaled bronchodilators and corticosteroids preand 3 months post-intervention. At baseline and followup, we recorded the patients' reported weekly use of these medications in the preceding one-month time period.

\section{Sample size calculation}

A previous study determined that a change in Dyspnea Index of 8 is considered the minimally clinically important difference (MCID) [17]. Using a power of 0.8 and alpha-error of 0.05 , at least 16 patients with pre- and post-intervention data would be needed.

\section{Data analysis}

Statistical analysis was carried out using SPSS (Statistical Package for the Social Sciences, Version 25, IBM Corp, Chicago, USA). Basic descriptive and frequency statistics were performed for patient demographics, comorbidities, and presenting symptoms. Paired sample t-test was used to compare pre- and post-intervention Dyspnea Index scores.

Wilcoxon signed-rank test to compare the differences in bronchodilator and corticosteroid use pre- and postintervention at both are considered non-parametric, discrete data.

\section{Results}

Thirty-four patients were referred for possible PVFM during the study period. Due to local referral patterns, nearly all the patients were referred by Pulmonology due to suggestive symptoms and/or the presence of inspiratory and expiratory flow restriction on pulmonary function tests (PFTs). Nine of these patients were excluded from our study due to presence of alternate diagnosis to explain their symptoms after clinical assessment. This included laryngeal pathologies such as functional voice disorders, subglottic stenosis, unilateral vocal cord paralysis and untreated lung pathology (Fig. 1).

Demographic information and relevant clinical information of the remaining 25 patients are summarized in Table 1. Twelve patients (48\%) had a diagnosis of wellcontrolled asthma at the time of assessment based on Pulmonology assessment. Thirteen patients had a comorbid psychiatric diagnosis (e.G. major depression, anxiety disorder, or bulimia nervosa). Typical triggers of PVFM reported by patients included gastroesophageal reflux disease (GERD), exercise, upper respiratory tract infections (URTIs), speaking and cold air (Table 1).

Of the 25 patients, 17 completed the Dyspnea Index questionnaire pre- and 3 months post-intervention, with statistically significant reduction in scores $(p<0.001)$ and a mean difference of 12.1 (Fig. 2). Wilcoxon signed rank test was performed on thirteen patients who reported using bronchodilators pre-intervention. Our results showed a significant decrease in average bronchodilator use at 3 months post-intervention $(\mathrm{Z}=-2.934$, $p=0.003$ ) (Fig. 3). Only two patients reported use of inhaled corticosteroids pre-intervention and both reported no use post-intervention. One patient was referred for further assessment by speech language pathology for

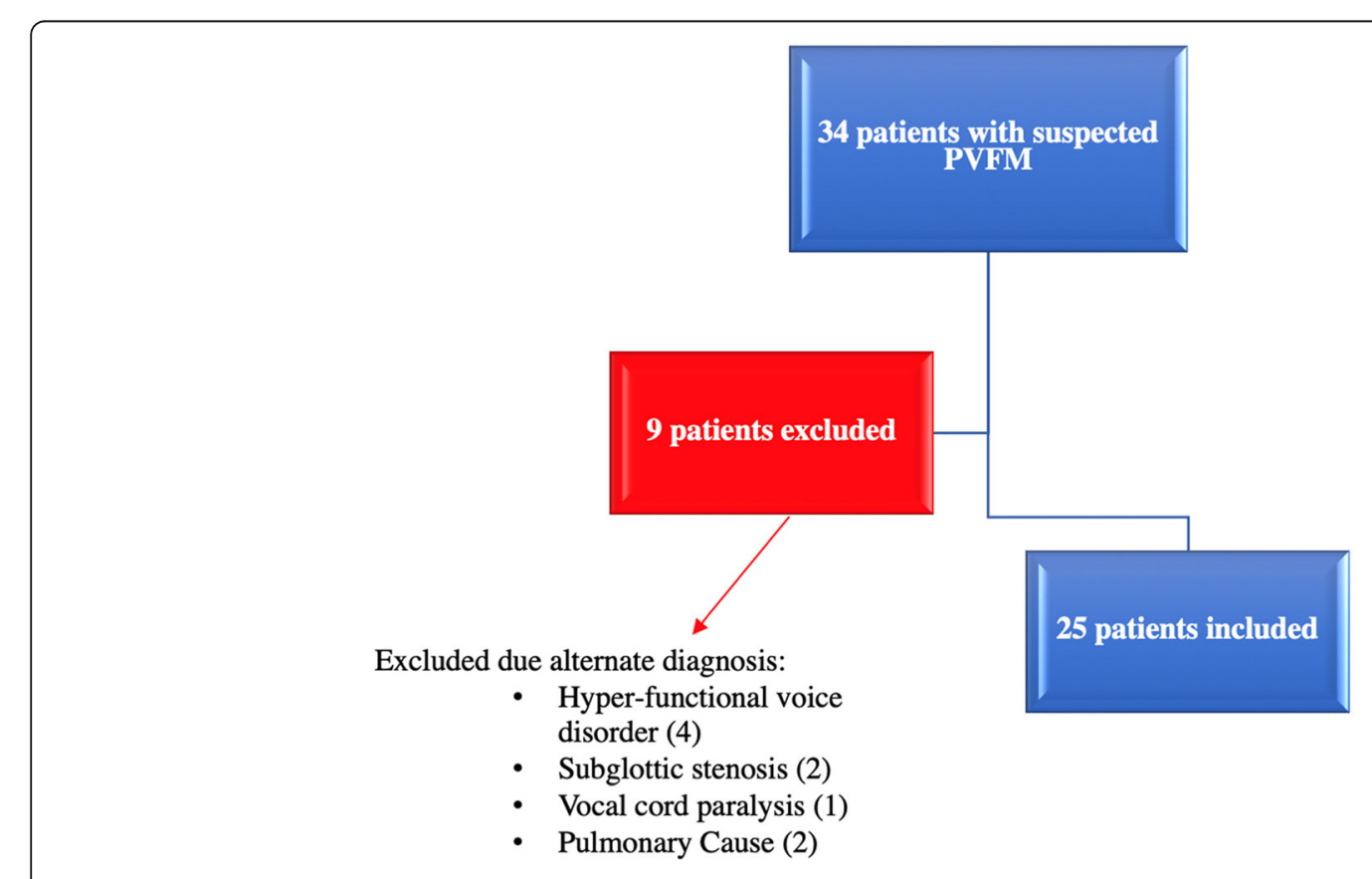

Fig. 1 Flow Chart of patient recruitment 
Table 1 Summary of Patient Demographics

\begin{tabular}{lll}
\hline & N & Percentage \\
\hline Sex & 7 & $28 \%$ \\
Males & 18 & $72 \%$ \\
Females & & \\
Mean Age \pm SD (Range) years & $36.9 \pm 14.4(17.0$ to 67.0$)$ & \\
Respiratory Diagnosis & & $48 \%$ \\
$\quad$ Asthma & 12 & \\
Psychiatric Diagnosis & & $28 \%$ \\
Depression & 7 & $24 \%$ \\
Anxiety & 6 & $8 \%$ \\
Other & 2 & \\
Triggers & & $52 \%$ \\
Environmental & 13 & $24 \%$ \\
Smoke & 6 & $12 \%$ \\
Exercise & 3 & $16 \%$ \\
Speaking & 4 & $8 \%$ \\
URTI & 2 & $4 \%$ \\
Cold Air & 1 & $4 \%$ \\
Emotional stress & 1 & $4 \%$ \\
GERD & 1 & \\
\hline
\end{tabular}

ongoing refractory symptoms. Eight patients did not attend an in-person follow-up at 3 months, and of these, six patients reported no residual symptoms by telephone follow-up. While all patients were contacted for a oneyear follow-up, twenty-three declined due to lack of symptoms and two patients could not be reached.

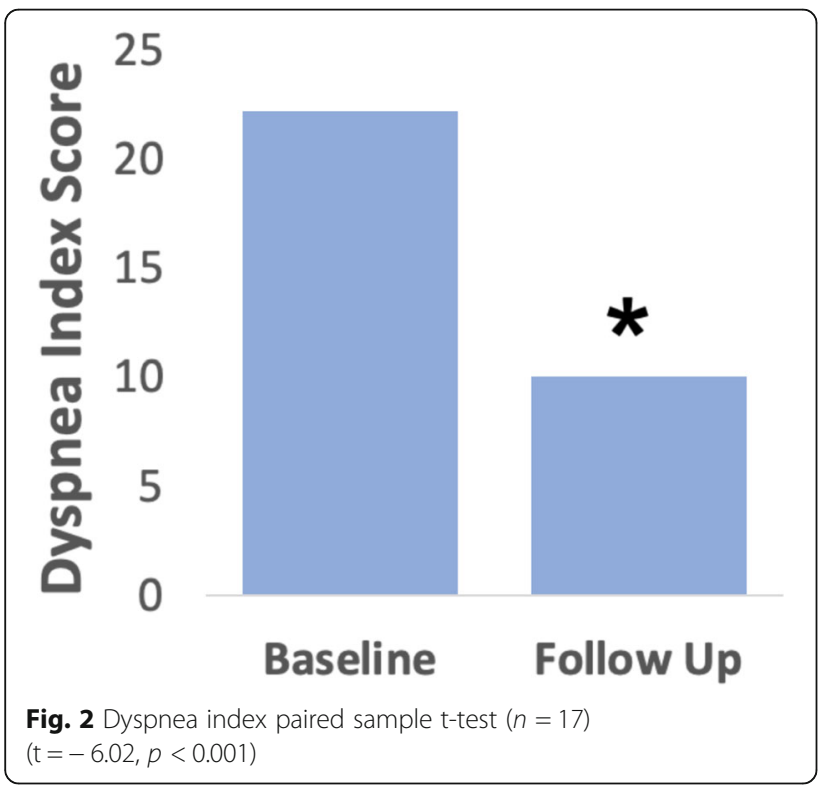

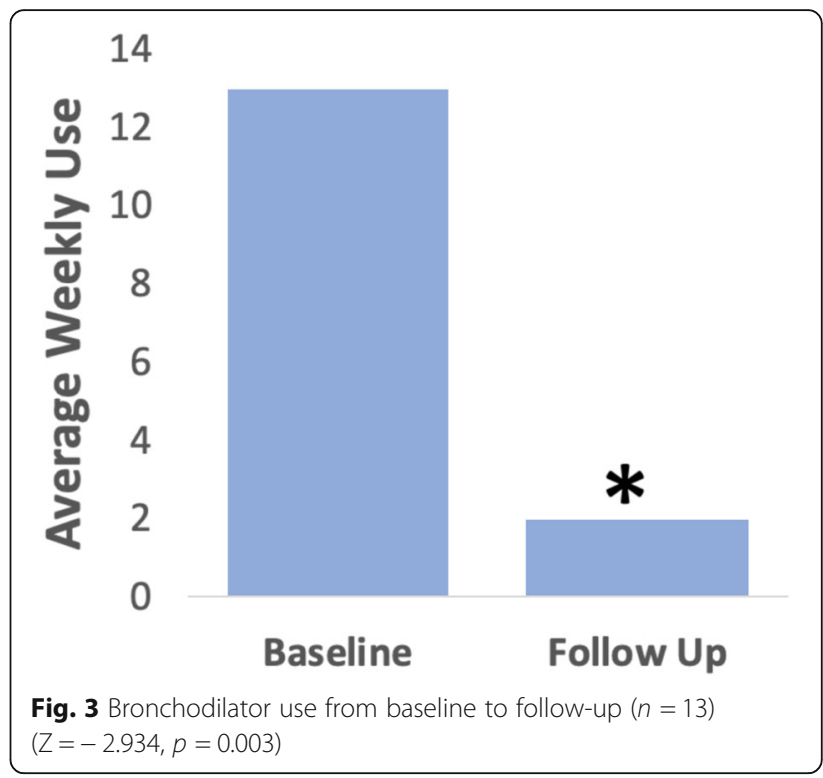

\section{Discussion}

We conducted a non-randomized, prospective study examining the use of surgeon-performed visual biofeedback in the management of PVFM patients. Our study provides support for its use in the initial management of patients presenting non-acutely, particularly in settings where specialized speech language pathology services are not readily available or delayed.

A variety of treatment options currently exist for the treatment of PVFM. This includes pharmacotherapy, counselling, laryngeal Botulinum toxin injection, education and behavioural therapy with respiratory retraining $[13,18]$. Treatment of concurrent medical conditions is crucial as it may exacerbate PVFM symptoms [19]. Visual biofeedback is easy to administer at the time of patient assessment by the Otolaryngologist. In addition to providing immediate reassurance, basic teaching regarding laryngeal anatomy and breathing techniques are provided immediately to the patient. It builds on existing studies demonstrating the efficacy of respiratory retraining and laryngeal control therapies to reduce PVFMrelated symptoms [13, 18-20]. Dr. Konstantin Buteyko first described these techniques for asthma patients, including a focus on nasal-breathing, breath-holding, and relaxation in the 1950's and multiple subsequent studies have demonstrated reductions in dyspnea symptoms, inhaler use and improved quality of life in asthmatic patients [21-26]. Later on, Blager, Gay \& Wood in 1988 described the first behavioural interventions for patients with habitual cough and vocal cord dysfunction, which is now largely used across the world [13].

There is a complex relationship between asthma and PVFM, as the two diagnosis are often confused and coexist. It has been reported that as many as 30 to $50 \%$ of 
patients with a diagnosis of asthma have a coexisting diagnosis of PVFM [27]. Almost half of our patients were diagnosed with asthma by a pulmonologist or primary care physician. It is unclear if the reduction in bronchodilator and inhaled corticosteroid use in our study is due to improved patient self-control of acute PVFM episodes versus improved self-management of asthma. However, our results are in line with other studies showing that improved PVFM control can reduce asthma medication use $[18,19]$. Kramer et al. demonstrated that patients with PVFM who received education and a course of laryngeal control therapy by a licensed speech language pathologist had reductions in the total use of asthma pharmacotherapy, including short and long acting betaagonists, inhaled and oral corticosteroids, leukotriene inhibitors and inhaled anticholinergic [18].

\section{Study limitations}

There are a few limitations to our study. The Dyspnea Index score is a global subjective dyspnea scale and was used as a surrogate for subjective PVFM control. Information regarding the actual change in number of episodes was not recorded. Our secondary outcomes of change in bronchodilator and inhaled corticosteroid use relies on patient memory and is subject to recall bias. In addition, this study focused on short-term follow-up of 3 months. Since most patients declined one-year follow-up, long-term outcomes data and recidivism over time could not be assessed. Finally, our study focuses on new PVFM patients rather than difficult-to treat or refractory patients. Specific populations, including elite athletes often have persistent symptoms despite routine therapeutic trials [28]. A recent study reported the use of the Olin EILOBI (Exercise Induced Laryngeal Obstruction Biphasic Inspiration) breathing techniques to reduce dyspneic symptoms in this specific patient population [29].

While our study did not record measures of healthcare utilization, such as visits to the emergency room, or previous intubations, this is an avenue of further research. Future studies could examine the potential reductions in healthcare costs due to avoidance of emergency room access, intubations and potentially intensive care unit stay.

\section{Conclusions}

Visual biofeedback shows a statistically and clinically significant reduction in symptoms and the use of asthma medication. Our study demonstrates an efficient and effective way of diagnosing and managing new patients with PVFM on the same day. We recommend visual biofeedback as a primary treatment for newly diagnosed PVFM patients.

\begin{abstract}
Abbreviations
DI: Dyspnea Index; EILOBI: Exercise Induced Laryngeal Obstruction Biphasic Inspiration; MCID: Minimally clinically important difference; PVFM: Paradoxical vocal fold motion; PFT: Pulmonary function test; SLP: Speech Language Pathology
\end{abstract}

\section{Acknowledgements}

N/A

\section{Authors' contributions}

$\mathrm{DA}$ and $\mathrm{CJ}$ completed the study design, collected and recorded the data. RL performed the data analysis and drafted the manuscript. All authors read and approved the final manuscript.

\section{Funding}

None.

Ethics approval and consent to participate

Prior to commencement of this study, ethics approval was obtained from the University of Alberta Health Research Ethics Board.

\section{Consent for publication}

N/A

\section{Competing interests}

The authors declare that they have no competing interests.

\section{Author details}

${ }^{1}$ Division of Otolaryngology Head and Neck Surgery, Department of Surgery, University of Alberta, 1E4 Walter Mackenzie Centre, 8440-112 Street NW, Edmonton, Alberta T6G 2B7, Canada. ${ }^{2}$ Faculty of Rehabilitation Medicine, University of Alberta, Edmonton, Alberta, Canada.

Received: 4 December 2020 Accepted: 19 January 2021

Published online: 18 February 2021

\section{References}

1. Halvorsen T, Walsted ES, Bucca C, et al. Inducible laryngeal obstruction: an official joint European Respiratory Society and European laryngological society statement. Eur Respir J. 2017;50(3):1602221.

2. Christensen PM, Heimdal JH, Christopher KL, Bucca C, Cantarella G, Friedrich G, Halvorsen T, Herth F, Jung H, Morris MJ, Remacle M, Rasmussen N, Wilson JA. ERS/ELS/ACCP task force on inducible laryngeal obstructions. ERS/ELS/ ACCP 2013 international consensus conference nomenclature on inducible laryngeal obstructions. Eur Respir Rev. 2015;24(137):445-50.

3. Newman KB, Dubster SN. Vocal cord dysfunction: masquerader of asthma. Semin Respir Crit Care Med. 1994;15(2):161-7.

4. Hicks M, Brugman SM, Katial R. Vocal cord dysfunction/paradoxical vocal fold motion. Prim Care. 2008;35(1):81-vii.

5. Patterson R, Schatz MM. Munchausen's stridor: non-organic laryngeal obstruction. Clin Allergy. 1974;4(03):307-10.

6. George S, Suresh S. Vocal cord dysfunction: analysis of 27 cases and updated review of pathophysiology \& management. Int Arch Otorhinolaryngol. 2019;23:125-30.

7. Denipah N, Dominquez CM, Kraii EP, Kraii TL, Leos P, Braude D. Acute management of paradoxical vocal fold motion (vocal cord dysfunction). Ann Emerg Med. 2017;69:18-23.

8. Newman KB, Mason UG. 3rd, Schmaling, K.B. clinical features of vocal cord dysfunction. Am J Respir Crit Care Med. 1995;152:1382-6.

9. Martin RJ, Blager FB, Gay ML, Wood RP. Paradoxic vocal cord motion in presumed asthmatics. Semin Respir Med. 1987;8:332-7.

10. Patel RR, Venediktov R, Schooling T, Wang B. Evidence-based systematic review: effects of speech-language pathology treatment for individuals with paradoxical vocal fold motion. Am J Speech Lang Pathol. 2015;24:566-84.

11. Morris MJ, Allan PF, Perkins PJ. Vocal cord dysfunction: etiologies and treatment. Clin Pulm Med. 2006;13:73-86.

12. Reitz JR, Gorman S, Kegyes J. Behavioral management of paradoxical vocal fold motion. Perspect Voice Voice Disord. 2014;24:64-70.

13. Blager FB, Gay ML, Wood RP. Voice therapy techniques adapted to treatment of habit cough: a pilot study. J Commun Disord. 1988;21:393-400. 
14. Pitchenik AE. Functional laryngeal obstruction relieved by panting. Chest. 1991;100:1465-7.

15. Baxter M, Ruane L, Phyland D, Leahy E, Heke E, Lau KK, Low K, Hamza K, MacDonald M, Bardin PG. Multidisciplinary team clinic for vocal cord dysfunction directs therapy and significantly reduces healthcare utilization. Respirology. 2019;24:758-64.

16. Morris MJ, Christopher KL. Diagnostic criteria for the classification of vocal cord dysfunction. Chest. 2010;138(5):1213-23.

17. Gartner-Schmidt JL, Shembel AC, Zullo TG, Rosen CA. Development and validation of the dyspnea index (DI): a severity index for upper airwayrelated dyspnea. J Voice. 2014;28(6):775-82.

18. Kramer S, de Silva B, Forrest LA, Matrka L. Does treatment of paradoxical vocal fold movement disorder decrease asthma medication use? Laryngoscope. 2017;127(7):1531-7.

19. deSilva B, Crenshaw D, Matrka L, Forrest LA. Vocal fold botulinum toxin injection for refractory paradoxical vocal fold motion disorder. Laryngoscope. 2019;129(4):808-11.

20. Marcinow AM, Thompson J, Forrest LA, de Silva BW. Irritant-induced paradoxical vocal fold motion disorder: diagnosis and management. Otolaryngol Head Neck Surg. 2015;153:996-1000.

21. Katz DH, Sella O, Golan H, Banai K, Van Swearingen J, Krisciunas GP, Abbott KV. Buteyko Breathing Technique for Exertion-Induced Paradoxical Vocal Fold Motion (EI-PVFM). J Voice. 2019;S0892-1997(19):30190.

22. Jack S, Rossiter HB, Pearson MG, Ward SA, Warburton CJ, Whipp BJ. Ventilatory responses to inhaled carbon dioxide, hypoxia, and exercise in idiopathic hyperventilation. Am J Respir Crit Care Med. 2004;170(2):118-25.

23. Cowie RL, Conley DP, Underwood MF, Reader PG. A randomised controlled trial of the Buteyko technique as an adjunct to conventional management of asthma. Respir Med. 2008;102(5):726-32.

24. Cooper S, Oborne J, Newton S, Harrison V, Thompson Coon J, Lewis S, Tattersfield A. Effect of two breathing exercises (Buteyko and pranayama) in asthma: a randomised controlled trial. Thorax. 2003;58(8):674-9.

25. McHugh P, Aitcheson F, Duncan B, Houghton F. Buteyko Breathing Technique for asthma: an effective intervention. N Z Med J. 2003;116:1187.

26. Prem V, Sahoo RC, Adhikari P. Comparison of the effects of Buteyko and pranayama breathing techniques on quality of life in patients with asthma a randomized controlled trial. Clin Rehabil. 2013;27(2):133-41.

27. Low K, Lau KK, Holmes P, Crossett M, Vallance N, Phyland D, Hamza K, Hamilton G, Bardin PG. Abnormal vocal cord function in difficult-to-treat asthma. Am J Respir Crit Care Med. 2011;184:50-6.

28. Chiang T, Marcinow AM, de Silva BW, Ence BN, Lindsey SE, Forrest LA. Exercise-induced paradoxical vocal fold motion disorder: diagnosis and management. Laryngoscope. 2013;123(3):727-31.

29. Johnston KL, Bradford H, Hodges H, Moore CM, Nauman E, Olin JT. The Olin EILOBI breathing techniques: description and initial case series of novel respiratory retraining strategies for athletes with exercise-induced laryngeal obstruction. J Voice. 2018;32(6):698-704.

\section{Publisher's Note}

Springer Nature remains neutral with regard to jurisdictional claims in published maps and institutional affiliations.

Ready to submit your research? Choose BMC and benefit from:

- fast, convenient online submission

- thorough peer review by experienced researchers in your field

- rapid publication on acceptance

- support for research data, including large and complex data types

- gold Open Access which fosters wider collaboration and increased citations

- maximum visibility for your research: over $100 \mathrm{M}$ website views per year

At BMC, research is always in progress.

Learn more biomedcentral.com/submissions 